\title{
TOPOGRAPHICAL CHANGES CAUSED BY THE 2016 CENTRAL ITALY EARTHQUAKE SERIES
}

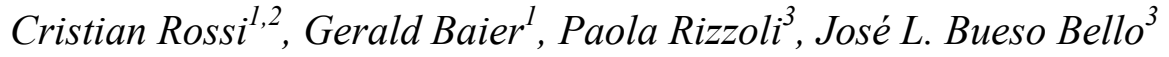 \\ ${ }^{1}$ Remote Sensing Technology Institute, German Aerospace Center (DLR), Germany \\ ${ }^{2}$ Satellite Applications Catapult, United Kingdom \\ ${ }^{3}$ Microwaves and Radar Institute, German Aerospace Center (DLR), Germany
}

\begin{abstract}
This paper presents the first results generated with the TanDEM-X mission for the monitoring of the topographical changes caused by the series of earthquakes that hit central Italy between summer and autumn 2016. For the purpose, two $300 \mathrm{~km}$ long data takes acquired between the Tyrrhenian and the Adriatic coasts and covering the October, 30, earthquake epicenter location have been considered. The takes have an about 5 years' temporal baseline, thus helpful to reveal the large and small scale terrain changes occurred after the 2016 seismic events.
\end{abstract}

Index Terms - DEM, earthquake, topography changes

\section{INTRODUCTION}

An intense seismic swarm has hit central Italy starting in summer 2016, with three main shocks. On August, 24, an earthquake of 6.2 moment magnitude scale took place in an area located at the borders of four Italian regions (namely Marche, Umbria, Lazio and Abruzzo), with the epicenter close to the small village of Accumuli. This earthquake severely damaged several towns, with collapses of many buildings, and 297 people have lost their lives [1]. A few days after the earthquake, InSAR data has been used to reveal the crustal deformation caused by the seismic event. A maximum subsidence of $20 \mathrm{~cm}$ close to the epicenter location has been reported in [2] by using ALOS-2 data. On October, 26, a 6.1 magnitude earthquake with epicenter about $28 \mathrm{~km}$ to the northwest of the August one, between the villages of Visso and Ussita, further damaged many infrastructures in the region. Four days later, on October, 30, a 6.6 magnitude earthquake struck in the proximity of Norcia, about $11 \mathrm{~km}$ to the south. Many topographical changes were documented after these two close events; some of them are represented in Fig. 1. A $10 \mathrm{~km}$ fracture reshaped Mount Vettore, in the proximity of the October, 30, epicenter, as visible in Fig. 1(a). The crack depth/fracture size has been reported to vary between $20 \mathrm{~cm}$ and $50 \mathrm{~cm} .60 \%$ of the buildings in Castelluccio di Norcia collapsed, as represented in the aerial picture in Fig. 1(b). Close to this village, visible terrain fractures and a $5 \mathrm{~m}$ deep sinkhole emerged and have been documented as in Figs. $1(\mathrm{c})$ and $1(\mathrm{~d})$, respectively.

Sentinel-1 imagery has been used to reveal and model the displacements followed by the earthquake. A maximum eastward shift of $40 \mathrm{~cm}$ in the proximity of Montegallo and a maximum westward of $30 \mathrm{~cm}$ in Norcia has been measured. Moreover, a vertical subsidence of $60 \mathrm{~cm}$ and an uplift of $12 \mathrm{~cm}$ has been reported in the Castelluccio di Norcia and Norcia areas, respectively $[3,4]$.

This work introduces direct topographical measures taken with the bistatic TanDEM-X mission, established to generate accurate Digital Elevation Models (DEMs), in order to confirm the large-scale measures taken with dInSAR techniques [3,4] and also reveal small-scale terrain changes, as for instance the ones in Fig. 1. Moreover, the paper aims to understand the capability and the limitations of the X-band system in terms of accuracy, linked to the detection and the assessment of post-earthquake damages and topographical changes.

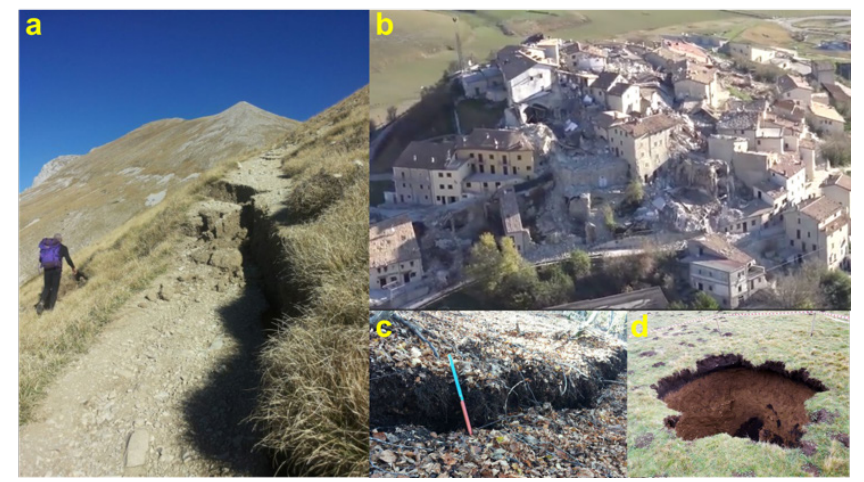

Fig. 1. Topographical changes caused by the October, 30, earthquake. (a) Crack in the Mount Vettore (CMimmo Catalucci/LifeGate) (b) Castelluccio di Norcia (CPaolo Galli/LaRepubblica) (c) Terrain subsidence (CPaolo Galli/LaRepubblica) (d) Sinkhole (CPeppe Caridi/Meteoweb) 


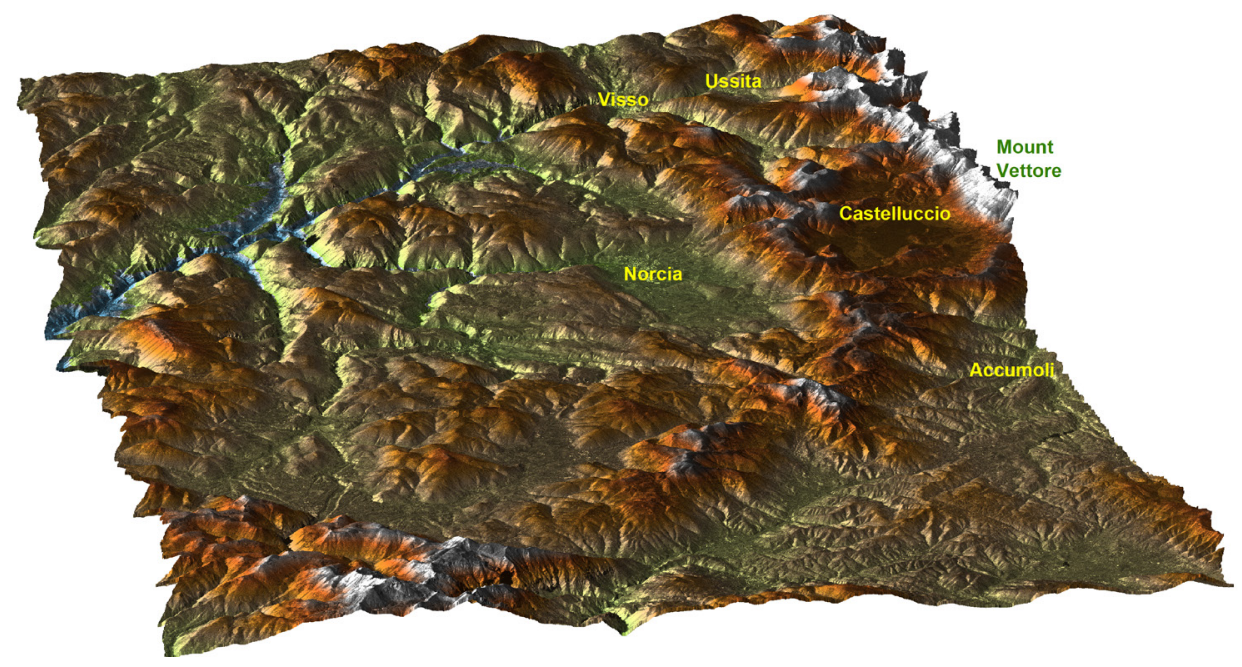

Fig. 2. Three dimensional view of the 2016 TanDEM-X DEM considered for this study.

\section{DATA DESCRIPTION}

The most straightforward way to estimate topographical changes is through DEM differencing. Considering the events under study, we chose to use an existing data take covering the epicenter of the October, 30, earthquake and to acquire new data with the same system geometry in order to avoid geometrically-related inaccuracies (e.g. different layover/shadow positions). The data take is spanning north to south between the towns of Cattolica (Adriatic coast) and Terracina (Tyrrhenian coast), for about $300 \mathrm{~km}$ and is about $30 \mathrm{~km}$ wide. To ease the interferometric processing, the full take is split in scenes of about $50 \mathrm{~km}$. For this preliminary study, we just consider the scene including the 6.6 magnitude earthquake epicenter, with the town of Norcia approximatively in the center of the scene. The reference TanDEM-X data was taken on October, 13, 2011, while the new acquisition has been performed two weeks after the event, on November, 14, 2016. The total temporal baseline is therefore slightly larger than five years. The main geometrical parameters of the two takes and of a complementary Sentinel-1 interferometric pair, used to compare repeat-pass dInSAR results to bistatic interferometry outcomes, are shown in Tab. 1.

The DEMs are generated using the Interferometric TanDEM-X Processor (ITP) [5], with a modification to the nominal processing that considers the use of a non-local filtering strategy for the phase noise reduction [6], to increase the overall quality. The interferogram horizontal resolution in Tab.1 refers instead to the nominal boxcar multilooking - simply considering the independent number of looks and the SAR pixel spacing, and it is annotated just to provide a comparison reference (although overestimated) to Sentinel-1, which is nominally processed. The final DEM grid spacing is set to about $3 \mathrm{~m}$.

Fig. 2 shows the three dimensional version of the DEM generated with the post-event data. The names of the towns mentioned in Sec. 1 are also annotated for reference. A first visual analysis of the DEM underlines the presence of many undulations, i.e. hills and mountains, suggesting the occurrence of geometrical distortions such as layover and shadow. Their impact in the DEM is well-known [7], basically yielding unreliable height information. The typical solutions to correct these distortions rely in the utilization of complementary acquisitions in different geometries. For this study, no additional acquisitions were planned, thus the impact of layover and shadow should be studied directly and the corresponding DEM pixels should be detected and discarded.

Sentinel-1 data has been interferometrically processed for the inclusion in the ESA Geohazard platform, with a final geographical raster sampling of about $50 \mathrm{~m}$. Fig. 3 shows the differential phase generated as one of the platform outputs and masked according to the TanDEM-X scene extension.

\begin{tabular}{|l|c|c|c|}
\hline & $\begin{array}{l}\text { TDX } \\
\mathbf{1 3 . 1 0 . 1 1}\end{array}$ & $\begin{array}{l}\text { TDX } \\
\mathbf{1 4 . 1 1 . 1 6}\end{array}$ & $\begin{array}{l}\text { S1 26.10.16 - } \\
\mathbf{0 1 . 1 1 . 1 6}\end{array}$ \\
\hline Inc. Angle [ ${ }^{\circ}$ ] & 38.6 & 38.4 & 39.6 \\
\hline $\begin{array}{l}\text { Baseline/Height } \\
\text { ambiguity [m] }\end{array}$ & $131 / 47.5$ & $118 / 52.7$ & $79 / 196$ \\
\hline $\begin{array}{l}\text { Interferogram } \\
\text { horizontal } \\
\text { resolution [m] }\end{array}$ & 9.3 & 9.3 & 35.5 \\
\hline
\end{tabular}

Tab. 1. Main geometrical parameters of the data used for the study. 


\section{OBJECTIVES AND FIRST RESULTS}

The main objectives of this study are:

a) Evaluate the large-scale vertical displacements followed the seismic event, as performed with InSAR data a few days after the shock [2][3]. To be noticed, the measure provided with bistatic interferometry is a direct and local measure not affected by possible artefacts (e.g. errors in the input DEM, atmosphere) which may occur in the dInSAR study. Nevertheless, main limitations of this direct measure are geometrical distortions, as aforementioned, and phase unwrapping errors. Regarding this last source of error, the in-processor detector [5] actually revealed the almost total absence of unwrapping errors.

b) Evaluate small-scale vertical displacements. The DEM sampling must be in this case taken into account. The final sampling is over a regular grid of approximatively $3 \mathrm{~m}$. Considering this sampling, a change detection on the building level, for instance to detect collapsed structures, is not feasible for small buildings, such as the ones in the villages affected, mainly due to the inability of the SAR system to properly map urban areas with a single acquisition. Instead, terrain ruptures like the ones in Fig. 1(a), 1(c) and 1(d), should be detectable. The main issue to their detection is the change intensity related to the system sensibility.

c) Evaluate the accuracy of change detection algorithms. DEM differencing must be carefully assessed. Changes due to temporal developments (e.g. deforestations, seasonal changes) should be distinguished from event-related changes. The relative accuracy of the double measure (2011 and 2016) should also be assessed depending on the mapped terrain.

Fig. 3 shows the co-seismic fringes generated with Sentinel1. As reported in [8], a complex displacement pattern with $30 \mathrm{~cm} / \mathrm{km}$ close to the epicenter, with minimum line-ofsight of $80 \mathrm{~cm}$ in the Castelluccio plain, can be derived with this imagery.

Fig. 4 displays the difference between the 2016 and the 2011 TanDEM-X DEMs. From this map, many considerations can be developed. First, this map provides the 5-years vertical changes in the region, including for instance clearings in the south-western portion of the map. Focusing on the epicenter location, it is evident a subsidence around mount Vettore, up to Norcia. The mean subsidence in the Castelluccio plain is $80 \mathrm{~cm}$, while the south wall of mount Vettore exhibits a larger mean subsidence of about $1.95 \mathrm{~m}$. The overall reshaping of this mount, with uplifts and depressions, is remarkable. The plain close to Norcia presents instead a mean uplift of $5 \mathrm{~cm}$. To generate the top map in Fig. 4, low-coherence pixels, representing temporal decorrelations mainly originated from geometrical distortions and water, have been masked and assigned to the null value. The pre and post event DEMs have been equally calibrated with the commercial TanDEM-X DEM only using the south-western quadrant, around the flat area surrounding Leonessa, assumed to be not affected by large topographical changes. This map has noticeable areas of apparent changes. A closer look at the changes revealed a clear correlation with forest areas, which cover large part of the region. More in detail, a lower scattering phase center of about $1-2 \mathrm{~m}$ is measured for the post-event DEM for broadleaved trees (e.g. beech trees), due to seasonal changes (November 2016 vs. October 2011) and a higher phase center of about $5-20 \mathrm{~cm}$ is measured for coniferous trees, probably due to their growth. Since the study shall focus on the event, a forest map, generated as in [9], has been used to discard these areas. The result is shown in the bottom map of Fig. 4. Although some misdetection is still present, the map results cleaned from seasonal changes and the focus goes towards the epicenter.

Fig. 5 shows temporal differences in the SAR amplitude and interferometric coherence. The third row presents the small town of Castelluccio as seen by the radar. Although the DEM is here locally inaccurate due to the typical distortions measured for buildings, the amplitude shows the damages through reflectivity attenuations. The fourth row of Fig. 5 shows the sinkholes that appeared in the Castelluccio plain as black spots in the interferometric coherence.

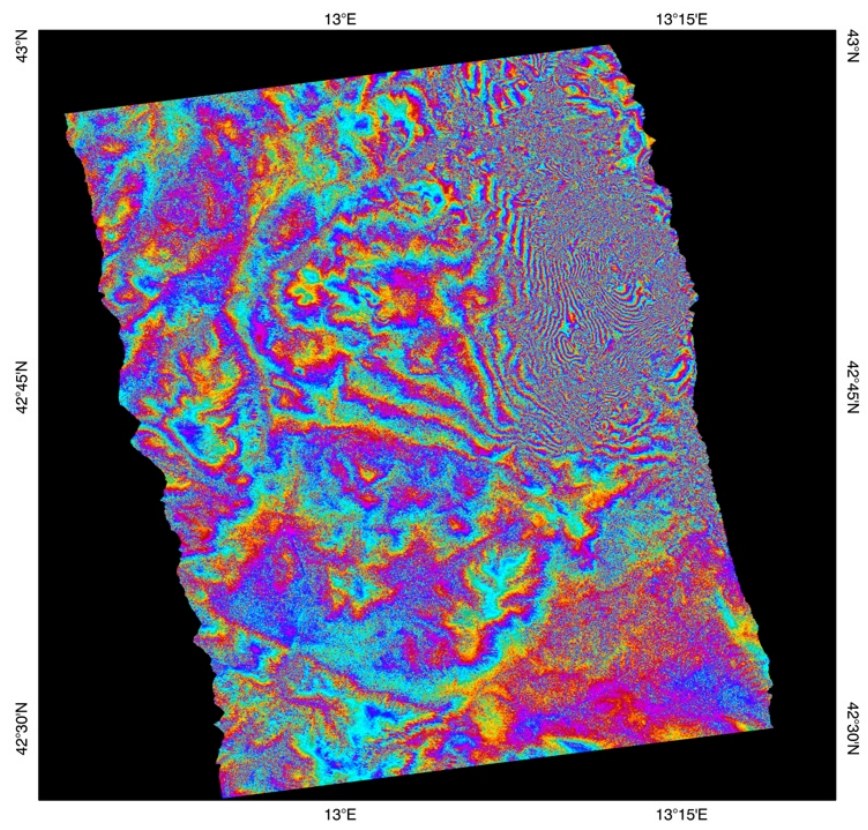

Fig. 3. Sentinel-1 differential phase generated with a pre-seismic and post-seismic acquisitions with 6 days temporal baseline. The SRTM DEM has been used for terrain compensation. This dInSAR phase is masked according to the TanDEM-X scene. 

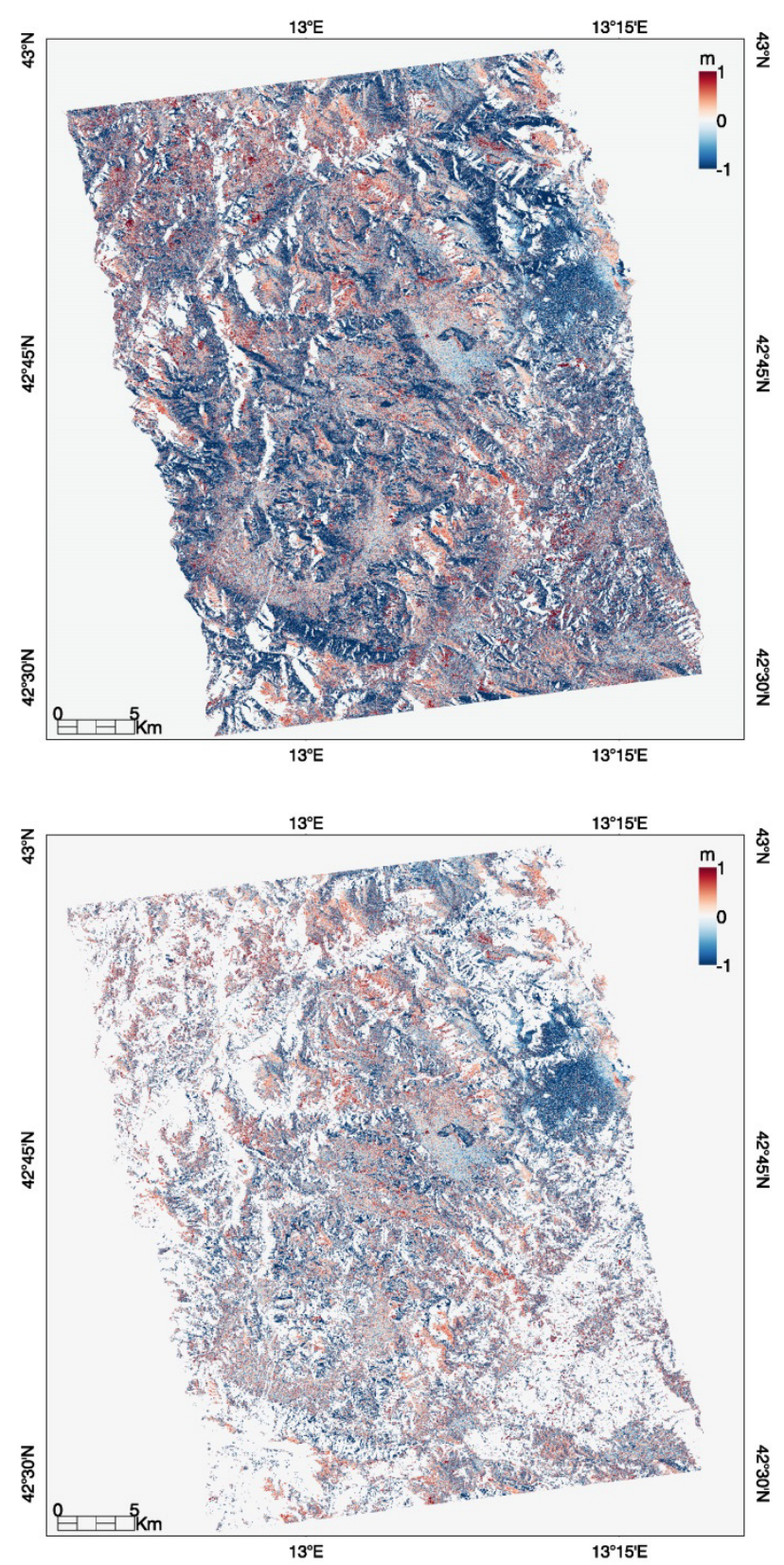

Fig. 4. Differential height between the 2016 and 2011 DEMs. (top) Geometrical distortions pixels have been masked and replaced with null value. (bottom) Forest areas have also been replaced with the null value, in order to better highlight the displacements caused by the seismic event.

\section{REFERENCES}

[1] "Terremoto centro Italia: cresce il numero vittime", Italian Civil Protection press release, 16.09.2016.

[2] "The August 2016 central Italy earthquake: crustal deformation detected by ALOS-2 data", Geospatial Information Authority of Japan press release, 26.08.2016.

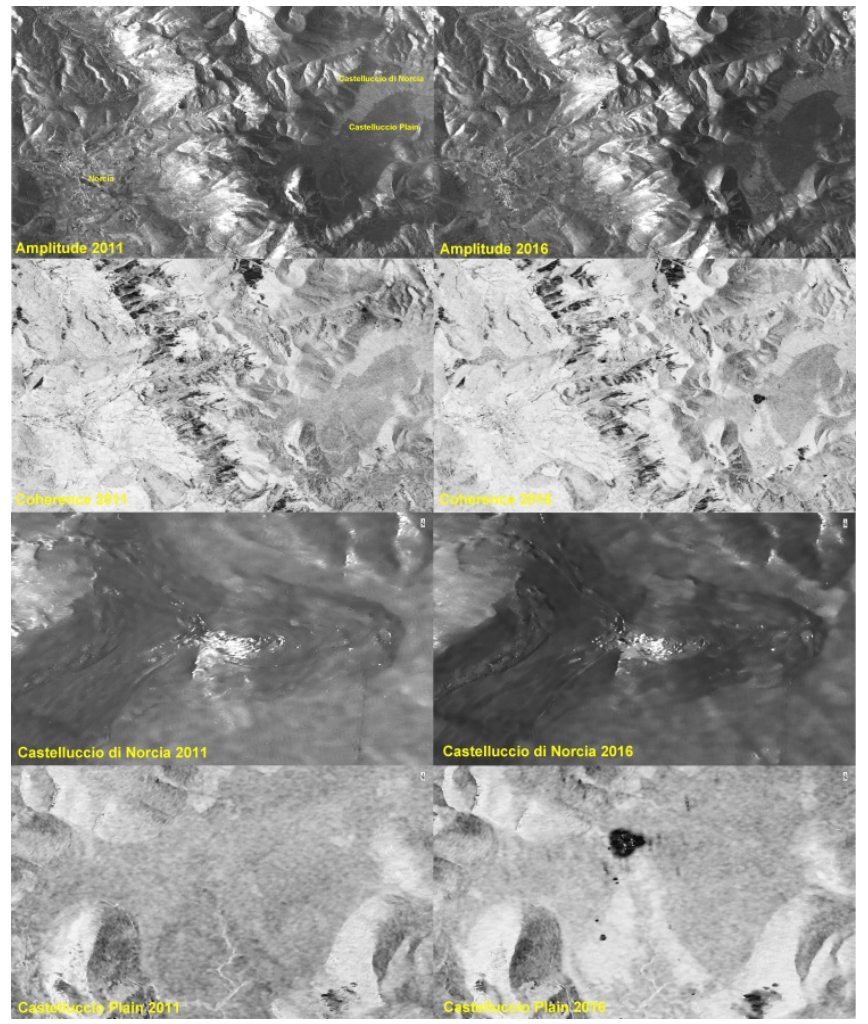

Fig. 5. SAR Amplitude and interferometric coherence variations between 2011, left column, and 2016, right column. (first row) SAR amplitude over the epicenter. (second row) Interferometric coherence over the same area. (third row) SAR amplitude over Castelluccio (fourth row) Interferometric coherence over the newly formed sinkholes.

[3] "Sentinel satellites reveal east-west shift in Italian quake", ESA press release, 03.11.2016

[4] Huang, M. et al., "Coseismic deformation and triggered landslides of the $2016 \mathrm{Mw} 6.2$ Amatrice earthquake in Italy", Geophysical Research Letters 44, 1266-1274, 2016.

[5] Rossi, C. et al., "TanDEM-X calibrated raw DEM generation.", ISPRS Journal of Photogrammetry and Remote Sensing 73 (2012): 12-20.

[6] Baier, G. et al., "Nonlocal InSAR filtering for high resolution DEM generation from TanDEM-X interferograms", Proceedings of IGARSS 2017.

[7] Eineder, M., "Problems and solutions for InSAR digital elevation model generation of mountainous terrain", Proceedings of FRINGE 2003.

[8] "Summary report on the 30 October, 2016 earthquake in central Italy $\mathrm{Mw}=6.5$ ", INGV report, 10.11.2016

[9] Wecklich, C. et al., "Production of a global forest/non-forest map utilizing TanDEM-X interferometric SAR data", Proceedings of IGARSS 2017. 